\title{
¿Eso es tradicional? Contextos, geografías y trayectorias musicales en la construcción de una noción sobre lo «tradicional». El caso del trío Los Cholos en Lima Metropolitana
}

\author{
Pablo Alberto Molina Palomino \\ Pontificia Universidad Católica del Perú \\ pmolina2005@gmail.com
}

RESUMEN

El presente artículo expone los resultados de un proyecto de investigación conducido entre 2011, 2012 y 2016 con el trio Los Cholos, en la ciudad de Lima, el cual buscó problematizar el sentido y uso dado a la noción de lo «tradicional» desde la práctica musical del conjunto en interacción con sus contextos de performance. Nuestro punto de partida fue no considerar tal término como un rasgo objetivo característico de una variedad de artefactos culturales, siguiendo retóricas de autenticidad o postulados académicos del folclor, sino como un principio abstracto construido a partir de un conjunto de significados, percepciones o valoraciones definidas por los intérpretes en el transcurso de sus trayectorias musicales. En ese sentido, no se buscó determinar qué es «tradicional» sino qué procesos operan para determinar la aplicabilidad de dicha categoría y los actores involucrados en ellos. Para esto se reconstruyeron las historias de vida de los integrantes de la agrupación y se condujeron sesiones controladas de exposición musical. Esto permitió observar que lo que entendemos por «tradicional» responde a un proceso que parte de la identificación de sonoridades y estilos, activando a su vez una serie de representaciones de lugar asociadas con geografias musicales y contextos abstractos de performance.

Palabras clave: música tradicional, trayectoria musical, geografía musical, percepción musical, contexto de performance. 
Is that traditional? Contexts, geographies and musical trajectories in the construction of a notion about what is «traditional». The case of Trío Los Cholos in the city of Lima

ABSTRACT

The present article exposes the results of a research project developed between 2011, 2012 and 2016 with Trio Los Cholos in the city of Lima, in which I sought to problematize the sense and use given to the notion of «traditional» within the musical practice of the ensemble, in interaction with its performance contexts. Our departure point was not to consider such term as an objective trait, characteristic of a variety of cultural artifacts according to authenticity rhetorics or academic folklore theories, but as an abstract principle constructed based on a set of meanings, perceptions or valuations defined by the ensemble's performers. In this sense, it is not sought to determine what is «traditional» but which processes operate to determine the applicability of that category and the actors involved in them. To do this, we reconstructed the life histories of the members of the ensemble and conducted controlled sessions of musical exposition. This allowed us to observe that what we understand as "traditional» responds to a process that starts from the identification of sonorities and styles, which in turn activates representations of place associated to musical geographies and abstract performance contexts.

Keywords: traditional music, musical trajectory, musical geography, musical perception, performance contexts. 
En 2006, a las pocas semanas de haber ingresado a la universidad, me uní al conjunto de música andina del Centro de Música y Danza de la Universidad Católica-CEMDUC ${ }^{1}$. Luego de haber aprendido a reconocer y ejecutar algunos estilos de huayno ${ }^{2}$, sería la primera vez que tendría la oportunidad de desarrollar una práctica musical grupal. El primer ensayo estaba por empezar cuando recibimos la visita de la investigadora y musicóloga Chalena Vásquez, entonces directora del CEMDUC, quien había venido a dar la bienvenida personalmente a los nuevos integrantes, así como a explicar el trabajo del centro en torno a la música.

«Aquí hacemos música peruana tradicional, no música latinoamericana», fueron las palabras que compartió y que, inadvertidamente, motivarían el posterior inicio de esta investigación, aunque en ese entonces dicha afirmación me generó más expectativas que interrogantes. Mi propia — aunque breve - experiencia de aprendizaje musical ya me había expuesto al uso de estas y algunas otras etiquetas ${ }^{3}$, mientras que mi participación en el CEMDUC validó su uso cotidiano. Había adoptado un código compartido por un colectivo extenso de individuos, apelando de manera intuitiva a una serie de percepciones y asociaciones para dar sentido a un complejo panorama de referencias y preferencias musicales.

1 Creado en 1992 tras la fusión de dos colectivos. El Grupo de Folklore de la Pontificia Universidad Católica del Perú (FOLK-PUCP) y el Núcleo de Arte Colectivo de la PUCP (NAC-PUCP), agrupaciones de música y danzas peruanas que ya operaban al interior de la PUCP desde 1975.

2 Fue mi padre, migrante de origen ancashino y sobreviviente de la ciudad de Yungay arrasada en 1970 por el terremoto y subsecuente aluvión, quien me enseñó a tocar la guitarra. El primer repertorio que me trasmitió fueron cinco huaynos ayacuchanos, para luego enseñarme el estilo de acompañamiento en guitarra de huaynos o chuscadas ancashinas.

3 Mi padre, por ejemplo, solía utilizar términos como «estilizado» y «comercial» para referirse a grupos de música cuya interpretación escapaba un poco de los estilos asociados con determinadas regiones del país, y a grupos cuyo nivel de interpretación musical era valorado como no muy elaborado. 
Sin embargo, a medida que avanzaba en mis estudios de antropología, empecé a problematizar la sostenibilidad de estas categorías y relativizar sus límites, poniendo especial atención en la idea de lo tradicional, dada su centralidad en los debates sobre la autenticidad en áreas como la etnomusicología (Myers, 2001), la antropología (Roel, 2000) y el folclor (Ben-Amos, 1972). Pero en lugar de intentar determinar qué era o no tradicional, busqué identificar qué tipo de significados y representaciones eran puestos en juego al usar esta noción para calificar la música interpretada por uno mismo, así como la interpretada por otros.

\section{DISCUTIENDO LO TRADICIONAL. ¿RASGO OBJETIVO O CONSTRUCCIÓN SUBJETIVA?}

En 1846, William J. Thoms acuñó la palabra folklore para reemplazar términos como popular antiquities o popular literature, buscando sistematizar dentro de un mismo campo de estudio la recolección de leyendas y tradiciones locales para su posterior conservación y análisis (Emrich, 1946). Su propuesta impulsó una nueva línea de investigación cuyos representantes, en el intento de legitimarse como una ciencia exacta, se concentraron en definir sus objetos de estudio, apelando para ello a la enumeración de múltiples rasgos descriptivos que en muchas ocasiones terminarían por superponerse o desplazarse (Morote, 1950, pp. 13-39). En los ámbitos regional y local, podemos ver este proceso a través del discurso de figuras clave que tomaron relevancia entre 1940 y 1970.

En Latinoamérica, uno de los principales promotores del estudio del folclor fue Carlos Vega, quien en 1944 definió este campo como la «ciencia de las supervivencias» (Vega, 1960, p. 177). Si bien dicho enfoque fue seguido en el Perú por varios investigadores, también fue rechazado por otros, como el antropólogo ayacuchano Efraín Morote. Rechazando la idea de «supervivencias», este concibió al folclor como una ciencia antropológica cultural responsable del estudio de lo que denominó «hechos folclóricos», definidos como manifestaciones anónimas, funcionales, plásticas, populares, ubicables, y tradicionales (Morote, 1950, p. 30). Así, el folclor pasaba de ser un ejercicio de descripción fragmentada a ser el estudio total de la cultura (Roel, 2000, p. 81).

El escritor y etnólogo José María Arguedas también contribuyó a conceptualizar el folclor, definiéndolo en 1964 como una ciencia dedicada al estudio del conocimiento tradicional, transmitido oralmente entre las clases inferiores e iletradas, y contrapuesto al conocimiento científico de las capas superiores y educadas de las «sociedades civilizadas» (Arguedas, 2007). En 1974, la antropóloga 
Mildred Merino de Zela propondría una nueva definición partiendo del concepto del continuum folk urbano de Robert Redfield, interpretando el folclor como un tejido social compartido entre élites y sectores tanto urbano-populares como campesino-rurales, constituido por las artes narrativas y musicales tradicionales (Merino de Zela, 2007).

Estos aportes, aunque expuestos de manera muy breve, permiten observar cómo la noción de lo tradicional fue reposicionándose en el discurso académico local. Así, de constituir uno entre varios rasgos adjudicados a los objetos de estudio del folclor, pasó a convertirse en un factor de distinción y posteriormente en un criterio de autenticidad transversal. Será sobre la base de estos marcos de análisis e interpretación que se generarán dicotomías discursivas entre tradiciones «puras» y «aculturadas», basándose en falsas suposiciones sobre el mayor valor de las primeras frente a las segundas (Kartomi, 1981). Y, del mismo modo, en estrategias como la exageración de algunos aspectos de la denominada música folclórica en relación con otros estilos musicales, para apuntalar tales divisiones (Carlin, 2004, p. 134).

Pero entre 1970 y 1980 varios autores plantearían cuestionamientos a tales argumentos. Eric Hobsbawm, por ejemplo, resaltó la naturaleza de las tradiciones como invenciones $(1988$, p. 8), creadas con la finalidad de inculcar valores y patrones de comportamiento en las personas. Mientras que Edward Schills (1971, p. 124) se enfocó en la falta de atención prestada a las formas o mecanismos a través de los cuales tales tradiciones se hacían efectivamente «tradicionales», atribuyendo dos posibles explicaciones para ello: o tal noción tenía demasiados significados asociados como para agruparlos y analizarlos, o simplemente carecía de significado alguno, por lo que su vigencia derivaba únicamente de su uso continuo al interior de la academia.

Desde otra perspectiva, el folclorista Dan Ben-Amos señaló que los criterios de creación colectiva, anonimato y simplicidad no eran definitorios sino más bien circunstanciales a la definición de folclor, exponiendo el carácter tradicional de esta como un recurso retórico y una construcción analítica empleada fundamentalmente por especialistas. En ese sentido, el autor no dudó en señalar la naturaleza eminentemente académica — antes que cultural — de la idea de lo tradicional dentro de los estudios de folclor (Ben-Amos, 1972). La etnomusicología llegaría a un balance similar. Como señalara Helen P. Myers:

A menudo el etnomusicólogo contemporáneo no tiene a dónde acudir a la hora de buscar palabras para explicar su trabajo, pues en las últimas décadas se le prohibió el uso de los términos vívidos y coloristas a los que antes 
recurría de forma constante... El término que sobrevivió al juicio de los años setenta fue «tradicional», pero aplicado a la música tiene que ver con todo y, consecuentemente, con nada (Myers, 2001, p. 29).

Sin embargo, en lugar de ser rebatidos, los marcos analíticos e interpretativos del folclorismo académico peruano ganaron solidez. Esto se hizo posible a través de una serie de simposios y congresos sobre folclor de nivel regional, nacional e internacional que tuvieron lugar desde la década de 1970 en adelante (Roel, 2000, p. 91). Así, las oposiciones discursivas entre lo tradicional y lo moderno se profundizaron, pese a ser construcciones histórico-culturales con límites y contenidos poco claros (Cánepa, 2001, p. 25), así como marcos de referencia simbólica alrededor de los cuales se generaron complejas dinámicas de interacción multidireccional (García Canclini, 1995). Esto se reflejaría en la continuidad de definiciones desconectadas de los debates recientes, que prescinden de mayores problematizaciones.

[...] por encima de tal maraña conceptual y expresado básicamente en dos o tres palabras, el folklore es hoy por hoy entendido como sinónimo de tradición popular o cultura popular y tradicional [...] El huayno es folklore cuando es antiguo, popular y consagrado en el tiempo por el pueblo, es decir, si se hace tradicional (Melgar Vásquez, 2006, pp. 46-47)

Es en medio de estos vaivenes teóricos que, de manera errática, la idea de lo tradicional ha ido apareciendo, desapareciendo y adoptando múltiples significados. Para unos, el término ha perdido toda relevancia y utilidad tras ser «desmentido» como una construcción o un invento. Para otros, se ha entronizado como un rasgo inherente a los elementos del folclor, haciendo doctrina de la tradición y transformándose más bien en «tradicionalismo» (Sanders, 1997, p. 88). Todo ello ha derivado en un fundamentalismo cultural que se exalta como preservador de la diversidad y la pureza mediante la cosificación de la cultura, concibiéndola como un todo compacto y territorializado (Grimsom, 2011, p. 65).

No obstante, cabe destacar que trabajos más recientes han puesto en entredicho este tipo de lecturas, evidenciando el protagonismo de los intérpretes en la definición de sus identidades musicales al transitar estratégicamente entre lo tradicional y lo moderno (Mendívil, 2004), rebatir la idea de lo tradicional y lo híbrido como opuestos irreconciliables en el campo de la producción musical contemporánea (Tucker, 2013), y advertir sobre el riesgo de no problematizar nuestras categorías discursivas y solo reemplazarlas con nuevos esencialismos envueltos en terminologías más sofisticadas (Bigenho, 2002, p. 23; Taylor, 2007, p. 160). 
En ese sentido, esta investigación sigue lo propuesto por autores como Allan Moore respecto de lo auténtico (2002) y Sydney Hutchinson sobre lo típico (2011), si bien desde otros tipos de prácticas musicales, en cuanto construcciones hechas en el acto de escuchar y a la relevancia de pensarlas engarzadas en identidades de lugar. Así, resulta fundamental pensar las tradiciones no como objetos sino como procesos (Cruces, 1998, p. 46), y discutir lo tradicional no como un rasgo definitorio sino como un principio abstracto (Sanders, 1997, p. 88), sin contenidos fijos o preestablecidos. Estos son definidos por los mismos intérpretes sobre la base del desarrollo de prácticas musicales individuales o colectivas desde la dimensión subjetiva de sus experiencias y el desarrollo de capacidades musicales, trascendiendo el ámbito académico.

\section{CONTEXTOS Y TRAYECTORIAS MUSICALES COMO ESPACIOS DE CONSTRUCCIÓN DE SIGNIFICADOS}

Las prácticas musicales, a través de las cuales se ha sugerido que los intérpretes confieren contenidos a la noción de lo tradicional, no pueden desvincularse de los contextos de performance en que tienen lugar, así como los procesos de transformaciones que atraviesan. Esta ha sido una de las principales cuestiones trabajadas por la etnomusicología desde sus inicios como un campo interdisciplinario, y en especial por la etnomusicología de la performance, en su búsqueda por entender la producción, organización y significación del sonido en medio de circunstancias históricas o culturales específicas (Madrid, 2009).

$\mathrm{Y}$ aunque, a juicio de algunos, este campo no logró generar un modelo de análisis sostenible o coherente debido a deficiencias y limitaciones tanto teóricas como metodológicas (Reynoso, 2006, pp. 225-240), generó puntos de partida conceptuales, como las ideas de «ocasiones musicales» y «ocasiones de performance»: las primeras, unidades socioculturales en las que se veían expresados formas y valores compartidos de sus estructuras y contextos sociales (Herndon, 1971, p. 341); las segundas, instituciones socioculturales inscritas en contextos definidos como marcos conceptuales y estructuras socioeconómicas particulares (Qureshi, 1987, p. 69).

Puede hallarse cierta continuidad entre estos aportes y lo que postula luego James Lull — si bien con un sentido más general—, sobre que, más allá de sus sonidos o significados, la música se origina y reside en los «mundos sociales y culturales» de las personas (Lull, 1992, p. 2). En ese sentido, los contextos de performance serán abordados no desde las ocasiones musicales o de performance 
como único tipo de práctica musical, sino desde las dimensiones tanto sociales como culturales en las que esta se desenvuelve, recurriendo a conceptos más específicos.

Para abordar la dimensión social de estos contextos se asumió que las prácticas musicales operan dentro y como parte de instituciones sociales más extensas (Lloréns y Chocano, 2009, p. 20). Esta premisa quizás queda mejor expuesta en términos de «mundos musicales» (Finnegan, 1989, p. 31) o «escenas musicales» (Peterson y Bennett, 2004, p. 1), en cuanto campos de relaciones sociales donde artistas, productores y seguidores asumen de forma interconectada y colectiva una serie de prácticas, estilos musicales y factores de distinción en función del gusto.

La dimensión cultural, por otro lado, se abordó desde el concepto de «entramados culturales», entendidos como un conjunto polidimensional y articulado de elementos musicales y extramusicales, pertenecientes tanto al ámbito de las ideas como al de las acciones y productos concretos (Martí, 2004, p. 11). Es al interior de estos donde empiezan a tomar forma códigos sistémicos compartidos por sus agentes participantes, plasmándose en un vocabulario particular, una serie de puntos de referencia comunes y un cuadro de valores compartidos intrínsecos (Martí, 2002, p. 260).

Así, el hecho de estar inmersos en contextos de performance implica que los sujetos desenvuelvan sus prácticas musicales en medio de un campo de relaciones e interacciones sociales, permeadas por un conjunto de significados, representaciones y valores compartidos. Estas prácticas, sin embargo, no se limitan a ocasiones musicales o de performance, sino que abarcan un vasto grupo de actividades, como la organización de eventos, la incorporación de nuevos participantes a las escenas, la creación de nuevos grupos musicales, la coordinación y conducción de ensayos, así como la aplicación de criterios y percepciones de valor (Lloréns y Chocano, 2009, p. 30).

Pero, con el paso del tiempo, las prácticas de los intérpretes delinean trayectorias musicales. La noción de «senderos musicales», entendidos como rutas de tránsito entre «mundos musicales», resulta de utilidad para abordar esto, pues hace posible evidenciar la naturaleza dinámica de las prácticas y explicitar las intersecciones entre distintas tradiciones musicales (Finnegan, 1989, pp. 306307). En ese sentido, con «trayectoria musical» me referiré a un proceso dinámico que toma forma a lo largo del tiempo en un marco cambiante de contextos de performance, y durante el cual se va entrando y saliendo de varios mundos o escenas musicales, así como definiendo un entramado cultural de significados al desarrollar competencias musicales. 


\section{APUNTES METODOLÓGICOS}

Para el desarrollo de esta investigación se tomó al trío de música y canto popular Los Cholos como estudio de caso. Formado en 1999 en la ciudad de Lima y activo hasta el día de hoy, el grupo se especializa en interpretar géneros de música andina, criolla y afroperuana, y en adaptar danzas asociadas a contextos festivos, productivos y rituales ceremoniales ${ }^{4}$. Para ejecutar este repertorio, sus integrantes emplean un formato instrumental compacto de charango, guitarra, quenas y dos voces, junto a otros instrumentos de viento o percusión. Su estilo se distingue por el protagonismo dado al charango como instrumento melódico en la mayoría de temas. La quena también adquiere una función melódica, mientras que la guitarra asume un rol de acompañamiento a través de rasgueos y bordones ${ }^{5}$.

El trabajo de campo para esta investigación se desarrolló en la ciudad de Lima entre agosto y octubre de 2011, de forma esporádica entre 2012 y 2013, y por último entre fines de 2015 e inicios de 2016, gracias al financiamiento del Programa de Apoyo al Desarrollo de Tesis de Licenciatura otorgado por la Pontificia Universidad Católica del Perú. Para el recojo de información, se aplicaron entrevistas a profundidad tanto a los integrantes del trío Los Cholos como a otros actores ligados a él. Esto permitió reconstruir las trayectorias musicales del grupo y sus integrantes. Del mismo modo, se llevaron a cabo sesiones de exposición musical controlada con el fin de recoger las percepciones y asociaciones construidas alrededor de la idea de lo tradicional.

Entre los entrevistados a quienes se aplicó esta herramienta estuvieron dos integrantes del trío Los Cholos, así como otros cuatro actores vinculados con sus prácticas y trayectorias musicales. Para seleccionar los temas utilizados se tomaron en cuenta criterios estéticos y valorativos, así como las geografías musicales representadas a través de los repertorios, advertidas durante el trabajo de campo. Esto permitió, hasta cierto punto, esbozar un rango esperable de reacciones entre nuestros entrevistados y ponerlas a prueba durante las sesiones.

4 Al finalizar esta investigación, el repertorio ejecutado por el trío Los Cholos sumaba un total de 66 temas. De estos, más del $80 \%$ correspondía a un género musical asociado con el espacio musical andino, siendo el huayno el de mayor presencia. Asimismo, el 50\% de todo el repertorio se correspondió con estilos y géneros musicales de la región Ayacucho.

5 «Rasgueo» designa el hecho de formar un acorde con la mano izquierda y golpear todas las cuerdas de la guitarra con la mano derecha, siguiendo el patrón rítmico del género musical que se está interpretando. «Bordón» hace referencia al acompañamiento de una melodía solo con las notas graves de la guitarra, siguiendo tanto el patrón rítmico como la estructura armónica. 


\section{PUNTOS DE ARTICULACIÓN. CONTEXTOS Y TRAYECTORIAS EN LA NUEVA CANCIÓN LATINOAMERICANA}

Integrado por Ricardo García en el charango, Jinre Guevara en los vientos (quena, sicus, waqrapukus) y percusiones (tinya, shacshas, cajón) además de primera voz, y Gómer Valverde en la guitarra y segunda voz ${ }^{6}$, las primeras prácticas musicales de los miembros del trío Los Cholos se dieron a inicios de la década de 1980, fuertemente marcadas por la nueva canción latinoamericana. Asociado desde su origen con un interés por fusionar las formas del folclor musical tradicional con letras socialmente relevantes (Morris, 1986, p. 117), la expansión de este movimiento artístico y cultural durante la década de 1960 configuró distintos tipos de «canción militante» en medio de un contexto de dictaduras militares (Vila, 2014, pp. 2-4). Hacia mediados de la década de 1970 ya se había generado una emergente — si bien limitada - escena de nueva canción en la ciudad de Lima (Oliart y Lloréns, 1984).

El establecimiento de puntos de articulación fue importante para su configuración, y espacios como el Taller de la Canción Popular jugaron un rol protagónico en ese sentido. Fundado en 1975 por el compositor académico Celso Garrido Lecca $^{7}$, quien retornó al Perú en 1973 tras más de veinte años viviendo en Chile, el Taller fue un programa de formación musical no curricular establecido en la Escuela Nacional de Música ${ }^{8}$ y dirigido a músicos populares que no contaban con educación musical formal. Tuvo como objetivo principal el «alfabetizar musicalmente» a sus participantes, de modo que pudieran «elevar y perfeccionar» su tratamiento de la música popular (Garrido Lecca, 2001, 2013). Para ello se les ofrecieron cursos de solfeo, teoría musical, armonía, contrapunto, quechua, lenguaje corporal y dominio escénico.

6 En 2015 se sumó un cuarto integrante al grupo, lo que volvió obsoleto el término «trío» para definirlo. No obstante, debido a que durante el período en que se desarrolló el principal trabajo de campo para esta investigación (2011-2012) el grupo se mantuvo como un trío, utilizaremos este término a lo largo de la tesis.

7 Destacado compositor piurano y miembro de la Generación del 50, grupo de compositores formados en el Conservatorio Nacional de Música, teniendo como mentores al belga Andrés Sás y al austriaco Rodolfo Holzmann. Entre los miembros de este grupo destacan figuras como Enrique Pinilla, Enrique Iturriaga, Edgar Valcárcel y César Bolaños. Llegó becado a Santiago de Chile en 1950 para estudiar en la Facultad de Ciencias y Artes de la Música de la Universidad de Chile. Así, completó los estudios de composición que había empezado años atrás en Perú, y generó estrechos vínculos con miembros importantes de la nueva canción chilena tales como Víctor Jara, Inti Illimani y Quilapayún.

8 En 1972 el general Juan Velasco Alvarado dispuso, mediante Decreto Ley No 19268, la absorción del Conservatorio Nacional de Música y otras escuelas de arte dentro del Instituto Nacional de Cultura. Al mismo tiempo, cambió su denominación por la de «Escuela Nacional de Música». 
El Taller respaldó e impulsó propuestas con una nueva estética en torno a la música popular latinoamericana, promoviendo la formación de varios grupos, como Tiempo Nuevo, Vientos del Pueblo, Puka Soncco, Tarpuy y Dúo Adagio. Pero también tuvo que lidiar con una fuerte oposición y rechazo al interior de la institución, ejercida por sectores del profesorado que subordinaban lo «popular» ante lo «académico» (Garrido Lecca, 2000). Asumir la dirección de la Escuela Nacional de Música en 1976 permitió a Garrido Lecca afianzar la posición del Taller, pero esto no lo libró de sus propias tensiones y conflictos internos, generados en torno a los límites de la apropiación y recreación musical.

Un ejemplo lo da uno de los ex integrantes del Taller, migrante ayacuchano llegado a Lima en 1973, y que antes de la aparición de tal espacio ya interpretaba en escenarios como coliseos folclóricos junto a su trío de música ayacuchana, llamado Los Rucanas. Un día, ya al interior del Taller, los integrantes del dúo Adagio propusieron tocar un huayno de su región usando bombo y pandereta, lo que generó una inmediata reacción de protesta.

Yo me molesté y le dije: «Maestro Celso, discúlpeme, pero eso para mí es un pecado mortal, no tiene nada que ver el bombo ni la pandereta en un huayno ayacuchano. Para eso nosotros tenemos banda, entonces ahí sí se le mete bombo. Pero cuando tocamos con cuerdas, bombo y pandereta no va». Entonces, primera contradicción en el taller, y me comenzaron a ver ya como ultra (B. Villegas, comunicación personal, 27 de noviembre de 2011).

Para el entrevistado, la instrumentación propuesta no encajaba con el tipo de género musical que quería interpretarse. El arreglo del Dúo Adagio contradecía lo que su propia experiencia le había enseñado, y sobre la que su condición de migrante le confería autoridad. Estos incidentes pondrían en evidencia los límites de la tolerancia ante la introducción de transformaciones en prácticas musicales asumidas como auténticas. Pero al mismo tiempo, permitirán entender cómo se construyó una escena local de nueva canción desde experiencias sociales de clase específicas y representaciones sonoras de etnicidad asociadas a ella.

Los grupos formados al interior del Taller de la Canción Popular se desenvolvieron junto con otros surgidos en paralelo, tales como N.E.P.E.R. ${ }^{9}$, Blanco

9 N.E.P.E.R. (Núcleo Estudiantil de Poetas y Escritores Realista-Radicales) fue formado por amigos de colegio a fines de la década de 1960 y se fortaleció en la década posterior con el ingreso de sus miembros a varias universidades. En 1981 grabaron el álbum ¡América Libertad! con temas de nueva canción y temas propios con fuerte crítica social. 
y Negro ${ }^{10}$, Alma América, Alturas ${ }^{11}$ y Amaru. Todos ellos fueron vistos como modelos a seguir ${ }^{12}$, o los profesionales de la escena ${ }^{13}$, definiendo un campo de distinción en función de sus afinidades por repertorios y posturas políticas. Un ejemplo de esto sería el uso de categorías como «chileno» y «panfletario».

Había otros grupos que nos criticaban, que nos decían que éramos «chilenos» y teníamos toda la corriente chilena. Pero lo hacían por política, y nosotros les decíamos que ellos eran unos «panfletarios», que mejor se dedicaran a la política y no a la música... cada uno cantaba el himno de su partido, canciones directas, sin poesía, sin metáfora ni nada (B. Villegas, comunicación personal, 27 de noviembre de 2011).

Se entendía que, mientras más politizado el grupo, el nivel de complejidad musical de sus propuestas era inferior. Aunque la falta de posicionamiento político alguno también fue vista como sinónimo de bajo nivel musical, como en el caso de los denominados kjarkeros o grupos cuyos repertorios imitaban al de Los Kjarkas y otros grupos bolivianos. En medio de este panorama, la inclusión de temas peruanos - y, más aún, tradicionales - se volvió un factor de distinción percibido de forma positiva en todos los niveles. Desde grupos consagrados como Amaru, descrito por nuestros informantes como «citadinos limeños que te investigaban la música más tradicional», con un repertorio descrito como absolutamente peruano y solo algunos temas bolivianos ${ }^{14}$, hasta grupos de ámbitos más barriales, como Takiq Mayu e Inti Nan ${ }^{15}$, en los que participaron miembros del trío Los Cholos.

O sea, a diferencia de otras agrupaciones que surgían, ellos [Takiq Mayu e Inti Ñan] tenían un poco la efervescencia de la música latinoamericana. Pero también de hacer música peruana, o con esas intenciones de hacer música peruana (J. Guevara, comunicación personal, 26 de agosto de 2011).

10 Formado a fines de la década de 1970 a partir de un grupo de teatro homónimo, llegó a grabar por lo menos un álbum en 1982 titulado Cantaclaro, en el que se incluyeron composiciones de nueva canción argentina y chilena, además de folclor boliviano y peruano, como Carnaval de Arequipa y Cilulo.

11 Fue creado en 1978 por miembros de la Tuna Universitaria Nueva Amistad - TUNA, un coro interuniversitario creado y dirigido por Aurelio Tello, reconocido musicólogo peruano.

12 I. Catacora, comunicación personal, 15 de mayo de 2012.

13 J. Sotelo, comunicación personal, 24 de agosto de 2011.

14 R. Concha, comunicación personal, 8 de febrero de 2016.

15 Takiq Mayu fue un grupo creado en 1980 que reunió a varios músicos del barrio donde vivían Gómer y Jinre, en el distrito limeño de San Martín de Porres. Gómer se integró a este grupo en 1983, pero se terminó disolviendo en 1984 con el fallecimiento de su fundador. Inti Nan se forma en 1983. Gomer se unió ese mismo año y Jinre un año después. 
En medio de este panorama, el contexto político cada vez más complejo de la segunda mitad de la década de 1980, marcado por la entrada del primer gobierno de Alan García, así como la expansión de Sendero Luminoso y el MRTA, motivaron la renovación de referentes musicales. Como indican los testimonios de nuestros informantes, hubo un quiebre con la dimensión más política de la nueva canción latinoamericana, dando paso a una versión depurada de música latinoamericana protagonizada por los kjarkeros $^{16}$ y la influencia cada vez mayor de la música folclórica boliviana (Céspedes, 1984, 1993).

En esa época pues estaba de moda la música boliviana... En los 70 fue una revolución de la nueva canción popular, la nueva canción chilena, y en los 80 fue una revolución con estos grupos bolivianos, pues, ¿no? Savia Andina, Kjarkas... (J. Sotelo, comunicación personal, 31 de enero de 2016).

Figura 1. Trayectorias musicales del trío Los Cholos

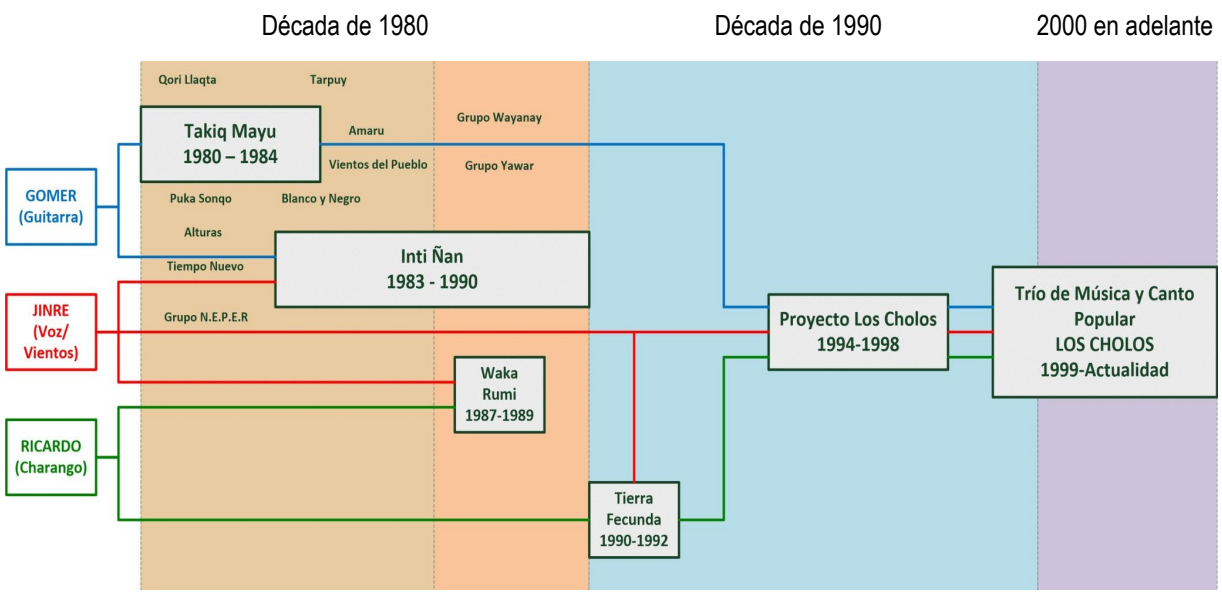

Al mismo tiempo que se daban estas transformaciones en los contextos de performance, los ahora integrantes del trío Los Cholos empezaron a tomar conciencia crítica de que la música latinoamericana no empataba con las experiencias de socialización musical de un público migrante, sino más bien con la búsqueda de identidad y experimentación sonora de sectores universitarios de clase media. En palabras de Carlos Iván Degregori (1981, p. 39), una expresión de su interés y necesidad por salir al encuentro de una raíz antigua o nacional

16 Entre estos habrían destacado grupos como Wayanay y Yawar, si bien el mapeo de este tipo de agrupaciones no fue el objetivo central de la presente investigación. 
en medio de una época de polarización social. Esto evidenciaría no solo quiebres de audiencias, sino también de repertorios y criterios de valor entre la afirmación de lo latinoamericano y la reivindicación de lo peruano.

\section{PUNTOS DE QUIEBRE. DE LO LATINOAMERICANO A LO PERUANO TRADICIONAL}

Como se observa en la figura 1, antes de reunirse en el trío Los Cholos en 1999 y el antecedente directo de este grupo, denominado «Proyecto Los Cholos» en 1994, tanto Jinre como Gomer y Ricardo integraron grupos de música latinoamericana y peruana ${ }^{17}$. Takiq Mayu, Inti Ñan, Waka Rumi y Tierra Fecunda ${ }^{18}$ fueron espacios de aprendizaje a través de los cuales experimentaron los cambios en los contextos de performance antes descritos y una serie de puntos de quiebre, como en el caso de Ricardo durante un ensayo de Tierra Fecunda.

Como director del grupo, Ricardo propuso tocar el huayno ayacuchano Lucía, pero las cantantes del conjunto se negaron aduciendo que ese tipo de música no era de su agrado. Este rechazo llevó a Ricardo a acusarlas de «acomplejadas», pues, según su opinión, para ellas cantar un huayno ayacuchano equivalía a una aberración o a cantar lo que cantaba la empleada, reforzando dicha apreciación en el hecho de que ambas estudiaban en un colegio «medio pituco» ${ }^{19}$. El gusto musical se volvió reflejo no solo de preferencias estéticas, sino también de posicionamientos de clase y etnicidad. Otro de los integrantes del trío Los Cholos haría una reflexión más específica sobre este aspecto:

También fui descubriendo que la chamba estaba también hacia adentro, o sea hacia el interior, hacia el trabajo sobre la música peruana. Que incluso desde la experiencia de la música latinoamericana muchas veces éramos desdeñosos con lo peruano. O sea, el intelectualismo entre paréntesis — ponle de izquierda, si te parece - era muy revolucionario latinoamericanamente hablando. Pero desde el punto de vista de afirmar lo peruano no era tan revolucionario (J. Guevara, comunicación personal, 19 de agosto de 2011).

17 Tierra Fecunda participó en el premio Takiy de folclor latinoamericano desarrollado en la Concha Acústica del Campo de Marte en 1991 y ganó la competencia. Una grabación de los temas interpretados por el grupo refleja un repertorio de compositores de diferentes países y vinculados con la nueva canción.

18 Waka Rumi fue un grupo formado en 1987 por un profesor de quena que dictaba cursos de extensión en el Museo de Arte de Lima. Fue la primera práctica musical grupal de Ricardo. Tierra Fecunda fue fundado por Ricardo reuniendo a ex integrantes de Waka Rumi.

R. García, comunicación personal, 11 de agosto de 2011. 
En este mismo sentido se expresó uno de nuestros informantes, quien resaltó que la mayoría de agrupaciones referidas «jamás hacían música vernacular, muy rara vez en todo caso, y que no se estaban respetando los patrones folclóricos» debido a la vocación política que estos perseguían ${ }^{20}$. Como sugiere uno de los pocos estudios de este período, no parece haberse dado un trabajo de reconocimiento o investigación de la música peruana, lo que generó un movimiento sin referentes nacionales definidos (Oliart y Lloréns, 1984, p. 79) ${ }^{21}$. No obstante, la reconfiguración de entramados culturales y escenas no sería un proceso abrupto de ruptura, sino más bien un giro progresivo mediado por nuevos espacios y actores.

Para Jinre, por ejemplo, la figura de Manuel Acosta Ojeda ${ }^{22}$ fue central. Se convirtió en su asistente en los programas radiales que conducía en radio Santa Rosa y radio El Sol, entre finales de la década de 1980 e inicios de la de 1990. Esta experiencia le permitió internalizar un marco de geografías musicales que luego volcará en la construcción de nuevos repertorios, poniendo a prueba su capacidad de reconocer tanto géneros como estilos musicales distintos, y de asociarlos con espacios o lugares específicos.

Era un reto para él: yo le mandaba una hualina de San Pedro de Casta, una marinera cusqueña, un chimayche de la selva, una pechada de Cajamarca, y el hombre se acordaba de cómo ha estado en todo el Perú. Le gustaba cómo armaba el tema porque le hacía chambear su cerebro, y hablaba de las teorías y todo lo demás. Entonces es así cómo se comienza a forjar una gran amistad de hermano mayor (J. Guevara, comunicación personal, 19 de agosto de 2011)

La experiencia de Ricardo, en cambio, no dependió de una sola figura o espacio. Su aproximación a estilos distintos de los de la nueva canción empezó a darse cuando en 1987 se aproxima al charanguista Jaime Guardia para «aprender estilos peruanos» ${ }^{23}$. Años después, el cantautor Hugo Carrillo ${ }^{24}$ le comentaría

20 A. Zevallos, comunicación personal, 18 de octubre de 2011.

21 Cabe resaltar que estudios más recientes han profundizado sobre la escena de la nueva canción ayacuchana en Lima, en el marco del contexto de violencia política que atravesó el Perú durante la década de 1980 (Mendívil, 2015). No obstante, esta etapa de la historia social de la música en el Perú sigue siendo un tema poco explorado.

22 Manuel Acosta Ojeda fue un destacado compositor de música criolla, autor de valses emblemáticos tales como Cariño, Madre, En un atardecer, Canción de fe y Chola linda. Sus temas fueron popularizados ampliamente por el trío Los Chamas y Los Troveros Criollos. Se desempeñó como conductor de múltiples espacios radiales, y en particular de Radio Nacional. Falleció en 2015.

23 R. García, comunicación personal, 11 de agosto de 2011.

24 Además de ser cantautor de huaynos en quechua, Hugo Carrillo es antropólogo y ha sido congresista de la República entre 2011 y 2016. El contacto de Ricardo con este último se dio a través de las clases de charango que este empezó a dar en el Museo de Arte de Lima. 
que su estilo estaba «bonito pero como con frac, así con terno muy fino», y le recomendó que visitara los locales donde toca la «paisanada» para aprender a tocar el charango «de verdad $»^{25}$.

Ricardo empezó a frecuentar el local del Sindicato de Artistas Folklóricos del Perú - $\mathrm{SAFP}^{26}$, donde los días domingos se solían reunir músicos y afiliados a dicha organización, en su mayoría de origen migrante. Ahí aprovechaba para sentarse en primera fila y aprender de los grupos de música, y en especial de los charanguistas que iban a tocar a dicho espacio. Pero al ver que Ricardo había traído su charango y los observaba fijamente, estos intérpretes solían voltear sobre su sitio para ocultar sus manos e impedir que aprendiera a tocar igual que ellos.

Las anteriores experiencias revelan cómo los estilos musicales valorados como tradicionales se vuelven recursos cuidadosamente resguardados, en tanto capitales simbólicos de distinción y de prestigio, cuyo aprendizaje es mediado y validado por un grupo de maestros que asumen el rol de guardianes de la tradición. Así, a medida que fueron desarrollando sus trayectorias musicales y atravesando por diferentes contextos, los integrantes del trío Los Cholos no solo obtuvieron una serie de lenguajes musicales y códigos estéticos compartidos, sino también la licencia para hacer uso de ellos.

Esto les daría versatilidad para alternar entre diferentes escenas en que la noción de lo tradicional es puesta en juego como parte de un entramado cultural compartido, que va desde la afirmación de lo peruano hasta su performance como parte de un sentido más extenso y diverso de lo latinoamericano.

\section{LO TRADICIONAL COMO SONORIDADES Y REPRESENTACIONES DE LUGAR}

Pero por sí solos estos testimonios no proporcionan suficiente información para acceder al ámbito de las percepciones. Para lograr este objetivo, y como fue descrito anteriormente, se realizaron sesiones de exposición musical controlada. Se utilizaron siete temas apelando a diversas fuentes, entre registros de música en campo editados por el Instituto Nacional de Cultura, grabaciones de intérpretes

\footnotetext{
25 R. García, comunicación personal, 11 de agosto de 2011.

26 En 1995 esta organización cambió su denominación por la de Sindicato de Trabajadores Artistas Folcloristas del Perú - SITAFP, y en 2006 la volvió a cambiar por la de Sindicato de Trabajadores, Artistas, Intérpretes, Autores, Compositores Folcloristas y Afines del Perú SITAFPERU.
} 
de música popular andina que ganaron auge y presencia entre las décadas de 1950 y 1960, del circuito limeño de nueva canción latinoamericana de las décadas de 1970 y 1980, e intérpretes más contemporáneos.

En cada sesión se solicitó a los participantes que describieran el estilo que adjudicaban a cada tema ${ }^{27}$, prestando atención a la identificación de marcadores sonoros en tanto sonidos con un valor especial para la comunidad de individuos (Truax, 1999). Seguidamente, se pidió que hicieran una evaluación más personal de la interpretación escuchada, indicando a qué lugares o espacios los hacía remitirse. A través de estas preguntas se buscó indagar sobre las relaciones establecidas, a partir de estímulos sensoriales, entre música y lugares. Por último, se planteó la pregunta — en caso el término no hubiera surgido espontáneamente- sobre si se valoraba la música como tradicional y por qué.

Uno de los primeros hallazgos fue que todos los participantes aplicaron un mismo proceso para evaluar a qué estilo correspondía cada canción. Así, al momento de escuchar los temas sus primeros comentarios se enfocaron en el tipo de instrumentos musicales empleados y el uso de determinados recursos en la interpretación musical. Respecto del tema Soy un pobre campesino, por ejemplo, todos convinieron en que se trataba de un huayno de estilo cusqueño, varios de ellos incluso lo asociaron a la provincia de Canchis debido a la melodía y la forma de acompañar con la bandurria, como si el ritmo estuviera al revés ${ }^{28}$. Curiosamente, el tema no estaba siendo interpretado por músicos cusqueños, sino por músicos huancavelicanos pertenecientes al pueblo Chopcca. Ninguno de los participantes contempló esta posibilidad.

Normalmente eso para mí era Cusco ¡Pero así! En el último jugaba todos mis boletos a que era Cusco, pero pucha Huancavelica... no lo tenía yo por ese lado. Yo lo que he escuchado de Huancavelica es mucho más emparentado con Ayacucho, ¿no? (R. García, comunicación personal, 15 de octubre de 2012).

27 Entiéndase por estilo a un lenguaje o sistema musical que consiste en una serie de estructura o reglas elementales de producción a la que responde la ejecución de una producción musical en particular, y que supone una combinación orgánica de elementos (Cruces, 1998, p. 37). Los huaynos suelen acompañarse siguiendo un compás sincopado compuesto por dos corcheas y una negra. No obstante, en algunas regiones del Cusco el patrón rítmico de acompañamiento del huayno altera el orden de los tiempos, lo que genera la sensación de que se acompaña al revés. Estas mismas características se observan en la música del pueblo Chopcca, en Huancavelica. 
Cuadro 1. Temas empleados en exposición musical controlada

\begin{tabular}{|l|l|l|}
\hline Intérprete & Tema & Género musical \\
\hline $\begin{array}{l}\text { Lorenzo Layme Escobar y Bertha } \\
\text { Quispe Soto }\end{array}$ & $\begin{array}{l}\text { Soy un pobre campesino / } \\
\text { Nuqa campesinum kani }\end{array}$ & Huayno \\
\hline Los Alegres de Chinchobamba $^{2}$ & $\begin{array}{l}\text { Ichik Sixto / Cuyacunapaj } \\
\text { Faltantsu }\end{array}$ & Chimaychi \\
\hline Jaime Guardia $^{3}$ & Jardín abandonado & Huayno \\
\hline $\begin{array}{l}\text { Agrupación Ccoriccoyllor de } \\
\text { Pitumarca }\end{array}$ & Marinera pitumarquina & Marinera y huayno \\
\hline Embajador de Quiquijana $^{5}$ & Helme & Huayno \\
\hline Vientos del Pueblo $^{6}$ & Flor de cactus & Sicuri \\
\hline Pelo D'Ambrosio & Alpaquitay & Balada andina \\
\hline
\end{tabular}

1 INC [Archivo Sonoro DPI] (2008). Ñuqa Chopccam Kani. Música Campesina de los Chopcca (Disco 2) [Archivo de audio]. Recuperado de https://soundcloud.com/archivosonorodpi/pobre-campesinom-kani-soy-un

2 Los Alegres de Chichobamba [neti2431] (10 de enero, 2009). CHIMAYCHI-Los Alegres de Chinchobamba-Ichik Sixto-Cuyacunapaj Faltantsu [Archivo de video]. Recuperado de https://www.youtube.com/ watch? $\mathrm{v}=$ DUKvEM7SBOc

3 Huayno recopilado e interpretado por Jaime Guardia en su álbum Con arpa y violín Vol. II.

4 La grabación fue obtenida de un disco de vinilo digitalizado. No se cuenta con mayores datos sobre el año de grabación o la casa disquera que lo lanzó originalmente.

5 El Embajador de Quiquijana, seudónimo de Efraín Cuba, fue un reconocido intérprete en el circuito de coliseos folclóricos entre las décadas de 1950 y 1970. A diferencia del usual carácter lento y triste del tema, su interpretación es más rápida y alegre, descrita como «tonera» por algunos de nuestros entrevistados.

6 Vientos del Pueblo [AldoElCaminante] (16 de enero, 2012). Vientos del Pueblo - Flor de Cactus [Archivo de video]. Recuperado de https://www.youtube.com/watch?v=AS09L2QGBYI

7 Pelo D'Ambrosio [latinoseternos] (9 de agosto, 2009). ALPAQUITAY-PATA AMARILLA VIDEO OFICIAL (Pelo D'Ambrosio) [Archivo de video]. Recuperado de https://www.youtube.com/watch?v=HobaQ02QBjc

Otros temas generaron mayores niveles de inspección. Este fue el caso del tema Marinera pitumarquina, cuyo irregular patrón rítmico, como la multiplicidad de instrumentos — arpa, violín, mandolina y quenilla —, dificultaron el identificar marcadores sonoros que remitieran a geografías musicales específicas. Esto contrastó con el caso previo, donde el sonido y rasgueo de la bandurria llevó a una afirmación más bien categórica. En este caso, los participantes se centraron en aspectos específicos, como la velocidad picada o acelerada de la interpretación y el uso de la quenilla, instrumento asociado a contextos rurales, para descartar opciones. Aun así, ligaron el tema a contextos como Ayacucho, Cusco y Áncash. 
La adscripción del tema a un estilo y geografía regional se disolvió por completo en dos de los temas: Flor de cactus y Alpaquitay. El primero fue escuchado solo por dos de los participantes, quienes reconocieron a Vientos del Pueblo como su intérprete, un grupo salido del Taller de la Canción Popular y que por tanto era de un contexto urbano desde el cual hacían una apropiación de un sicuri puneño. En el segundo caso, todos los participantes señalaron que se trataba del reflejo de una experiencia totalmente urbana, dirigido hacia una audiencia citadina, sin hacer referencia a una región específica. En tal sentido, el espacio urbano de la ciudad fue visto como uno carente de referencias sonoras a geografías regionales.

Esto pertenece al género de la nueva canción urbana, la música andina urbana... Claro, esta es ya una movida recontra, totalmente urbana, ya totalmente urbana. Pero mira, estos son resultados de la década del setenta, resultado de la nueva canción popular, toda esa vaina (J. Sotelo, comunicación personal, 31 de enero de 2016).

Ello no significa que lo urbano sea un ámbito carente de marcadores sonoros, sino que estos operan en otro nivel de asociaciones entre música y lugar, remitiendo ya no a geografías regionales sino a espacios o contextos imaginados. Del mismo modo en que los participantes asociaron lo urbano con los últimos dos temas, también vincularon el resto de temas con situaciones geográfica y socialmente diferenciadas. Soy un pobre campesino, por ejemplo, evocó imágenes de ruralidad campesina, empleando términos como «pueblos bien adentro» para describirlas. Otros participantes lo ligaron a las «alturas» y la «geografía de los Andes», debido a la percepción de una intención por evocar sonidos de la naturaleza como el viento o el agua.

A partir de la evaluación de elementos específicos, tales como la afinación inexacta de los instrumentos, además de la percepción de cierta naturalidad o espontaneidad en la intención de la interpretación en quechua, los participantes reconstruyeron escenarios ideales de lo andino, inscribiendo el estilo musical identificado dentro de una geografía regional específica. Esto hizo que el tema fuera uno de los considerados «muy tradicionales». Pero este nivel de coincidencias entre representaciones musicales y espaciales no siempre ocurría, lo que pudo advertirse en el chimaychi Ichik Sixto / Cuyacunpaja faltantsu, y en los huaynos Jardín abandonado y Helme, que mostraran la relatividad de estas asociaciones.

En el primer caso, por ejemplo, se repitió el mismo esquema observado con el tema antes comentado. La mayoría de participantes identificaron el estilo a partir de la introducción con violines, la que funcionó como marcador sonoro asociado al género musical del chimaychi. Por otro lado, la interpretación fue descrita 
como «chuta»o «muy pueblerina» ${ }^{29}$, y la sonoridad de los instrumentos musicales asociada con las «alturas» ${ }^{30}$. El único elemento que interrumpió brevemente la alegoría sonora de una ruralidad andina fue la introducción de una batería eléctrica en la instrumentación del tema, aunque no con la suficiente intensidad como para ser descartado por los participantes como un tema no tradicional. Por el contrario, fue admirado por la destreza percibida en los músicos.

Bueno, la música va cambiando... Qué bonita música. Mira, a pesar de la batería que lo hace un poquito más digerible para el oído de nosotros de repente, igual se siente la sinceridad de la música (R. García, comunicación personal, 19 de octubre de 2012).

En cambio, con los huaynos Jardín abandonado y Helme, o la Marinera pitumarquina, sí se generaron quiebres en la manera como estos fueron asociados con determinados escenarios y contextos. Jardín abandonado, por ejemplo, no generó consenso entre los participantes, pues la mayoría de estos lo describieron como un tema representativo no de un estilo regional, sino del estilo personal de Jaime Guardia. Para los integrantes del trío Los Cholos, en cambio, dada la cercanía con este maestro a lo largo de sus trayectorias musicales, este tema fue visto como representativo del charango de Parinacochas, Ayacucho, al construir un vínculo sonoro con dicha región a través del instrumento y la voz del intérprete.

Es la tierra cantando, es como escuchar a Mercedes Sosa, una cosa así. Yo siento la tierra cantando cuando canta Jaime, su voz es telúrica y su charango es increíble. Ellos son los maestros, pues (R. García, comunicación personal, 19 de octubre de 2012).

En el caso de Helme y Marinera pitumarquina, resaltó que ambos fueron asociados a música interpretada en un escenario por la cantidad de instrumentos y la intuición de una preparación por los músicos, quienes se estarían presentando ante una audiencia o por contrato. Ninguno de estos temas fue vinculado con paisajes o geografías andinas, sino más bien con un espacio «de pueblo no necesariamente campesino ${ }^{31}$. Son precisamente estos temas a los que no se llega a adjudicar por completo el apelativo de tradicional, a diferencia de los que se han analizado anteriormente y que hasta llegan a ser catalogados como «muy tradicionales»o 0 «súper tradicionales» ${ }^{32}$.

\footnotetext{
29 G. Valverde, comunicación personal, 30 de septiembre de 2012.

30 R. Concha, comunicación personal, 27 de febrero de 2016.

31 J. Sotelo, comunicación personal, 31 de enero de 2016.

32 G. Valverde, comunicación personal, 30 de septiembre de 2012.
} 
Algunas participantes les adjudicaron tal apelativo, pero haciendo la atingencia de que eran «menos tradicionales» que otros, como Marinera pitumarquina, por dar la impresión de ser una interpretación derivada de un mayor nivel de ensayo. Menos espontánea y «más estudiada» ${ }^{33}$. En tal sentido, lo que estas asociaciones demuestran es que existen múltiples representaciones y asociaciones de lugar que van desde la adscripción a geografías musicales, hasta la evocación de escenarios y contextos imaginados, a partir de los cuales se definen niveles de tradicionalidad antes que polos excluyentes de tradicional/no tradicional. Estas representarían extremos de una escala en la que se dan entrelazamientos de percepciones y representaciones, como hemos podido observar, en función del cotejo entre la experiencia auditiva inmediata y las competencias desarrolladas a lo largo de trayectorias musicales individuales y colectivas. Hemos tratado de representar estas escalas en el siguiente cuadro.

Cuadro 2. Asociaciones y representaciones de tradicionalidad

\begin{tabular}{|c|c|c|c|c|c|c|c|}
\hline \multirow{2}{*}{ Intérprete } & \multicolumn{2}{c|}{ Tema } & \multicolumn{5}{c|}{ Participante } \\
\cline { 3 - 8 } & & 1 & 2 & 3 & 4 & 5 & 6 \\
\hline $\begin{array}{c}\text { Lorenzo Layme y } \\
\text { Bertha Quispe }\end{array}$ & $\begin{array}{c}\text { Soy un pobre } \\
\text { campesino }\end{array}$ & & & & & & \\
\hline $\begin{array}{c}\text { Los Alegres de } \\
\text { Chinchobamba }\end{array}$ & $\begin{array}{c}\text { Ichik Sixto / Cuya- } \\
\text { cunapaj Faltantsu }\end{array}$ & & & & & & \\
\hline $\begin{array}{c}\text { Jaime Guardia } \\
\text { Jardín abandonado }\end{array}$ & & & & & & \\
\hline $\begin{array}{c}\text { Ccoriccoyllor de } \\
\text { Pitumarca }\end{array}$ & $\begin{array}{c}\text { Marinera } \\
\text { pitumarquina }\end{array}$ & & & & & & \\
\hline $\begin{array}{c}\text { Embajador de } \\
\text { Quiquijana }\end{array}$ & Helme & & & & & - & - \\
\hline $\begin{array}{c}\text { Vientos del Pueblo } \\
\text { Flor de cactus }\end{array}$ & - & - & - & - & $\begin{array}{c}\text { Latinoameri- } \\
\text { cano }\end{array}$ \\
\hline Pata Amarilla & Alpaquitay & & Música urbana / No hay estilos \\
\hline
\end{tabular}

33 A. Zevallos, comunicación personal, 21 de febrero de 2016. 
Los recuadros resaltados en la parte superior (en verde) representan aquellos temas en los que las percepciones de los participantes enlazaron la representación de espacios geográficos con los espacios imaginados, resultando en una fuerte afirmación de tradicionalidad. Esta se irá diluyendo a medida que nos desplazamos hacia el extremo más urbano de dicho espectro (en anaranjado), en el que las referencias a geografías regionales desaparecen, dejando solo la asociación con una noción imaginada de urbanidad. En el medio podemos observar temas sobre los cuales la opinión de los participantes estuvo dividida y que resultan de suma importancia para el análisis, pues son una representación gráfica de la subjetividad desde las cuales se construyen estas representaciones.

\section{LA CONSTRUCCIÓN DE LO TRADICIONAL COMO UN ENCADENAMIENTO DE PERCEPCIONES}

Las sesiones de exposición musical controlada aplicadas mostraron que lo tradicional en la música se define mediante un proceso de percepciones y asociaciones entrelazadas, tomando la identificación de sonoridades y estilos a través de «marcadores sonoros» (Truax, 1999) como puntos de partida. Así, aspectos tales como el uso de ciertos instrumentos musicales, géneros o formas musicales, y técnicas de ejecución musical, son situados al interior de un esquema coherente de geografías sonoras adquiridas en el transcurso de las trayectorias observadas.

Esto significa que los estímulos auditivos están mediados o atravesados por las experiencias subjetivas de los oyentes e intérpretes, quienes recurren a la evocación de panoramas sonoros y contextos abstractos de performance para conferirles sentido y valor. Esto se condice con lo planteado por John Connell y Chris Gibson, que se refirieron a lo popular en la música como un ámbito o contexto social en el que se definen identidades musicales espaciales, generando nociones de autenticidad al incrustarse en geografías concretas de experimentación que se entrelazan con percepciones cotidianas de lugar (Connell y Gibson, 2002, pp. 1-19).

Es en función de esta concatenación de factores, como se muestra en la figura 2, que se establece la «tradicionalidad» de determinadas performances o prácticas musicales. Decir que algo es tradicional se vuelve, entonces, un ejercicio de reafirmación de geografías musicales al interior de un mapa mental de representaciones de lugar, una noción que se adscribe a las performances como una forma de autenticarlas antes que de describirlas (Moore, 2002, p. 220), activando reacciones que son no solo valorativas sino principalmente emocionales dentro de una comunidad de escucha (Hutchinson, 2011, p. 256). 
Figura 2. Proceso de construcción de lo tradicional
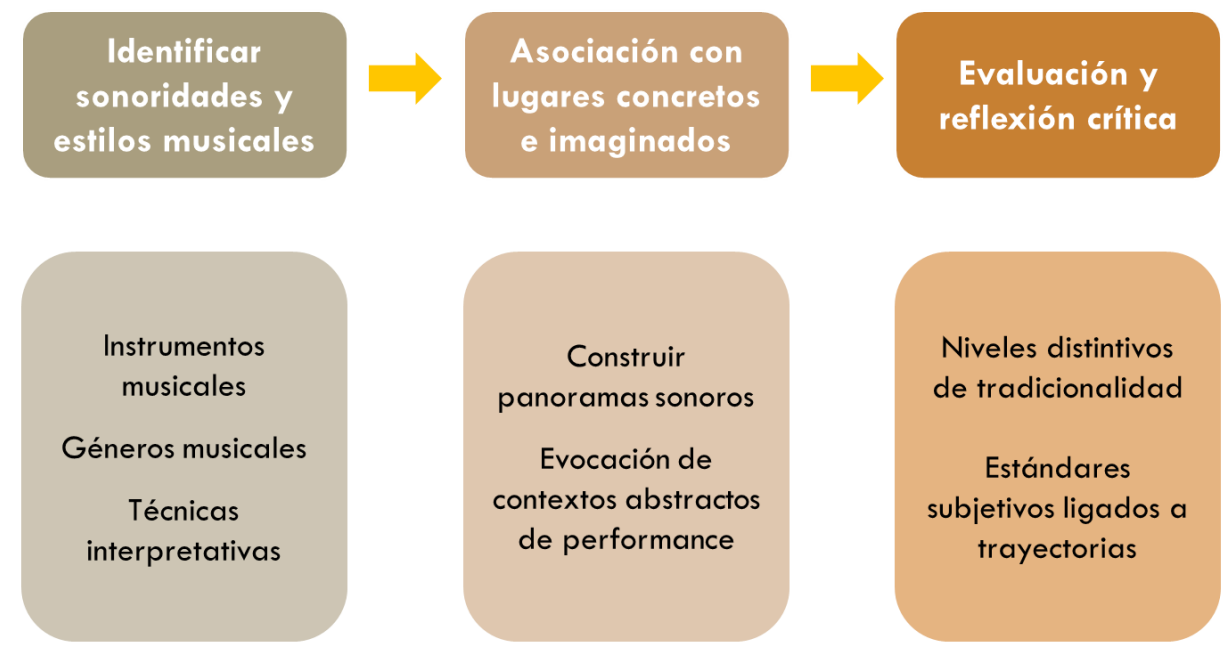

No obstante, cabe resaltar que estas geografías musicales, en tanto se construyen sobre la base de marcadores sonoros, pero también de experiencias subjetivas, funcionan como marcos aparentes de referencia antes que como un mapa de coordenadas exacto. Así, la dislocación de sonoridades y repertorios, advertida a través de las sesiones de exposición musical controlada, llama la atención sobre dos aspectos. Por un lado, sobre cómo el ritmo con que se desplazan hoy en día las sonoridades, a través de medios de reproducción y escucha, no se condice con la velocidad con que se establecen geografías alrededor de ellas. Y por otro, que al hablar de «tradicional» (u otras nociones afines) no nos remitimos a un criterio unívoco o absoluto, sino a nociones que cobran sentido dentro de marcos específicos de significación y simbolización compartido por un grupo al que nos hemos referido antes como entramado cultural.

\section{REFERENCIAS BIBLIOGRÁFICAS}

Arguedas, José María (2007). ¿Qué es el folklore? En Enrique González Carré (ed.), Folklore y tradiciones populares: Arguedas, González Carré, Jiménez Borja, Merino de Zela, Morote Best, Muelle. Lima: PUCP. Instituto Riva-Agüero.

Ben-Amos, Dan (1972). Towards a definition of folklore in context. En Américo Paredes y Richard Bauman (ed.), Towards new perspectives in folklore. Austin: University of Texas Press. 
Bigenho, Michelle (2002). Sounding indigenous. Authenticity in Bolivian music performance. Nueva York: Palgrave Macmillan. https://doi.org/10.1007/978-1137-11813-4

Cánepa, Gisela (ed.) (2001). Identidades representadas: performance, experiencia y memoria en los Andes. Lima: PUCP. Fondo Editorial.

Carlin, Richard (2004). The Good, The Bad, and The Folk. En C. Washburne y M. Derno (eds.), Bad Music: The Music We Love To Hate. Londres: Routledge. https://doi. org/10.4324/9780203309049_chapter_8

Céspedes, Gilka Wara (1984). New currents in «Música Folklórica» in La Paz, Bolivia. Latin American Music Review, 5(1), 217-242. https://doi.org/10.2307/780073

Céspedes, Gilka Wara (1993). «Huayno», «Saya», and «Chuntunqui»: Bolivian identity in the music of «Los Kjarkas». Latin American Music Review, 14(1), 51-101. https://doi.org/10.2307/780009

Connell, John y Chris Gibson (2002). Soundtracks: Popular music, identity and place. Londres y Nueva York: Routledge.

Cruces, Francisco (1998). Niveles de coherencia musical. La aportación de la música a la construcción de mundos. Antropología. Revista de Pensamiento Antropológico y Estudios Etnográficos, 15-16, 33-57.

Degregori, Carlos Iván (1981). El otro ranking: de música folclórica a música nacional. La revista de arte, ciencia y sociedad, 4, 34-39.

Emrich, Duncan (1946) Folk-Lore: William John Thoms. California Folklore Quarterly, 5(4), 355-374. https://doi.org/10.2307/1495929

Finnegan, Ruth (1989). The Hidden Musicians: Music-making in an English town. Cambridge: Cambridge University Press. https://doi.org/10.2307/2072980

García Canclini, Néstor (1995). Culturas híbridas. Estrategias para entrar y salir de la modernidad. Buenos Aires: Sudamericana.

Garrido-Lecca, Celso (2000). Celso Garrido Lecca (4 de 6) El trabajo con Víctor Jara y la Nueva Canción en Chile y Perú (C. Vásquez y M. Martínez, entrevistadores) [Archivo de video]. Recuperado de https://www.youtube.com/ watch?v=bzOZRF94AgI

Garrido-Lecca, Celso (2001). Celso Garrido Lecca: «La sociedad peruana no ha integrado al músico» (M. I. Guerra, entrevistadora). Recuperado de http://www. andes.missouri.edu/andes/Cronicas/MIG_GarridoLecca.html

Garrido-Lecca, Celso (2013). Celso Garrido Lecca: «Un artista no debe repetirse a sí mismo» (A. Gallegos, entrevistador). Recuperado de http://www.beethovenfm. cl/celso-garrido-lecca-un-artista-no-debe-repetirse-a-si-mismo/ 
Grimsom, Alejandro (2011). Los límites de la cultura. Crítica de las teorías de la identidad. Buenos Aires: Siglo XXI.

Herndon, Marcia (1971). The Cherokee Ballgame Cycle: An Ethnomusicologist's View. Ethnomusicology, 15(3), 339-352. https://doi.org/10.2307/850634

Hobsbawm, Eric (1988). The invention of tradition. Cambridge: Cambridge University Press.

Hutchinson, Sydney (2011). Típico, folklórico or popular? Musical categories, place, and identity in a transnational listening community. Popular Music, 30(2), 245-262. https://doi.org/10.1017/S0261143011000055

Kartomi, Margareth J. (1981). The Processes and Results of Musical Culture Contact: A Discussion of Terminology and Concepts. Ethnomusicology, 25(2), 227-249. https://doi.org/10.2307/851273

Lloréns, José Antonio y Rodrigo Chocano (2009). Celajes, florestas y secretos: una historia del vals popular limeño. Lima: Instituto Nacional de Cultura.

Lull, James (ed.) (1992). Popular music and communication. Newbury Park, CA: Sage Publications.

Madrid, Alejandro (2009). ¿Por qué música y estudios de performance? ¿Por qué ahora?: una introducción al dossier. Trans. Revista Transcultural de Música, 13.

Martí, Josep (2002). Las culturas musicales vistas a través de la perspectiva de los entramados culturales. En C. Fauria y Y. Aixelà (eds.), Barcelona, mosaic de cultures (pp. 255-266). Barcelona: Edicions Bellaterra.

Martí, Josep (2004). Transculturación, globalización y músicas de hoy. Trans. Revista Transcultural de Música, 8. Recuperado de http://www.sibetrans.com/trans/articulo/188/transculturacion-globalizacion-y-musicas-de-hoy

Melgar Vásquez, Alejandro (2006). Elementos de Folklore y Folklorología. Lima: Arteidea.

Mendívil, Julio (2004). Huaynos híbridos: estrategia para entrar y salir de la tradición. Lienzo, 25, 27-64.

Mendívil, Julio (2015). Representing Ayacucho: Music, politics, commerce, and identity in an Andean music scene in Lima. En J. Mendívil y C. Spencer (eds.), Made in Latin America: Studies in popular music. Londres: Routledge.

Merino de Zela, Mildred (2007). Hacia una teoría del folklore peruano. En E. González Carré (ed.), Folklore y tradiciones populares: Arguedas, González Carré, Jiménez Borja, Merino de Zela, Morote Best, Muelle. Lima: PUCP. Instituto Riva-Agüero. 
Moore, Allan (2002). Authenticity as Authentication. Popular Music, 21(2), 209-233. https://doi.org/10.1017/S0261143002002131

Morote, Efraín (1950). Elementos de folklore: definición, contenido, procesamiento. Cusco: Universidad Nacional del Cusco.

Morris, Nancy (1986). Canto Porque es Necesario Cantar: The New Song Movement in Chile, 1973-1983. Latin American Research Review, 21(2), 117-136. Recuperado de http://www.jstor.org/stable/2503359

Myers, Helen (2001). Etnomusicología. En F. Cruces (ed.), Las culturas musicales. Lecturas en Etnomusicología (pp. 19-40). Madrid: Trotta.

Oliart, Patricia y José Antonio Lloréns (1984). La nueva canción en el Perú. Comunicación y Cultura en América Latina, 12, 73-83.

Peterson, Richard A. y Andy Bennett (2004). Introducing music scenes. En A. Bennnett y R. A. Peterson (eds.), Music scenes. Local, translocal and virtual (pp. 1-16). Nashville, TN: Vanderbilt University Press.

Qureshi, Regula (1987). Musical sound and contextual input: A performance model for music analysis. Ethnomusicology, 31(1), 56-86. https://doi.org/10.2307/852291

Roel Mendizábal, Pedro (2000). De folklore a culturas híbridas: rescatando raíces, redefiniendo fronteras entre nos/otros. En C. I. Degregori (ed.), No hay país más diverso: Compendio de antropología peruana (pp. 74-122). Lima: Red para el Desarrollo en las Ciencias Sociales en el Perú.

Sanders, Karen (1997). Nación y tradición: cinco discursos en torno a la nación peruana, 1885-1930. Lima / México, D.F.: Pontificia Universidad Católica del Perú / Fondo de Cultura Económica.

Schills, Edward (1971). Tradition. Comparative Studies in Society and History, 13(2), 122-159. https://doi.org/10.1017/S0010417500006186

Taylor, Timothy D. (2007). Beyond exoticism. Western music and the world. Durham y Londres: Duke University Press. https://doi.org/10.1215/9780822389972

Truax, Barry (1999). Handbook for Acoustic Ecology. Recuperado de http://www.sfu. ca/sonic-studio/handbook/Soundmark.html

Tucker, Joshua (2013). Producing the Andean Voice: Popular music, folkloric performance, and the possessive investment in indigeneity. Latin American Review, 34(1), 31-70. https://doi.org/: 10.7560/LAMR34102

Vila, Pablo (2014). The Militant Song Movement in Latin America. Chile, Uruguay, and Argentina. Lanham, MD: Lexington Books. 